تأثير تيمار يس از برداشت استفاده از يوشش كيتوزان بر حفظ كيفيت موز رقم كاونديش در طى انبارمانى سرد (Musa acuminata cv. Cavendish)

\author{
مهديه كريمى'، مرجان السادات حسينى 'و سيد مرتضى زاهدى

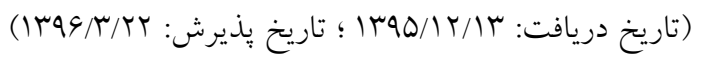

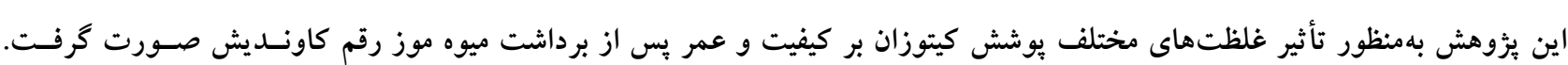

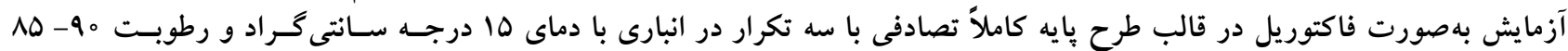

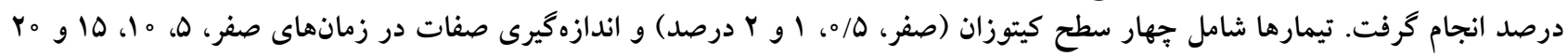

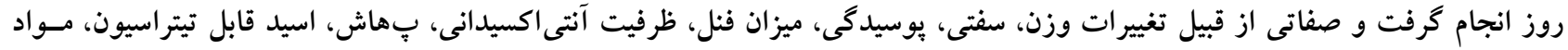

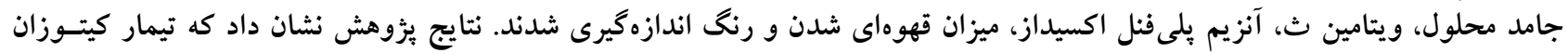

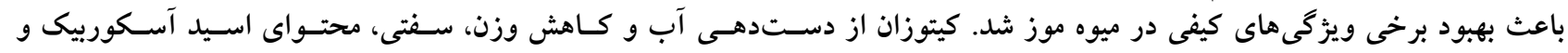

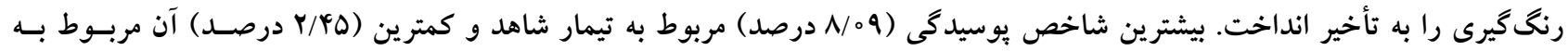

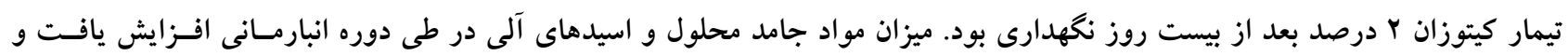

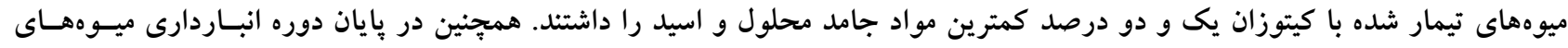

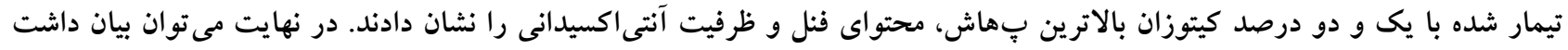

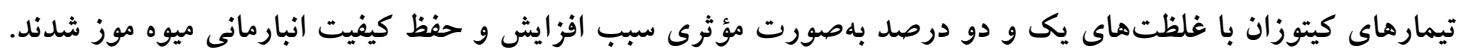

وازههاى كليدى: ظرفيت آنتىاكسيدانى، اسيد آسكوربيك، بلى فنل اكسيداز، شاخص بوسيدگى

1. دانشجوى دكترى گروه علوم باغبانى، دانشكده كشاورزى، دانشكاه بوعلى سينا، همدان

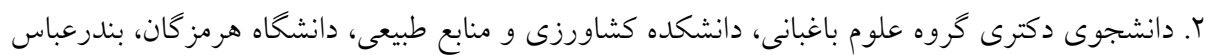

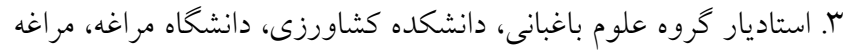

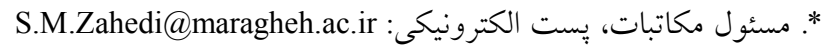


كيتوزان با فرمول شيميايى

طبيعى بعد از سلولز است كه در اسكلت خارجى سخت بوسيوستان،

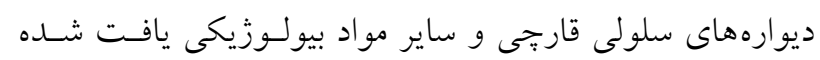

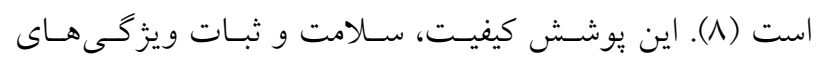

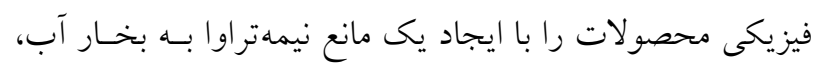

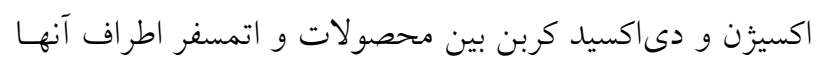

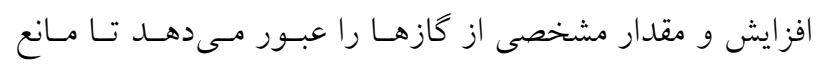

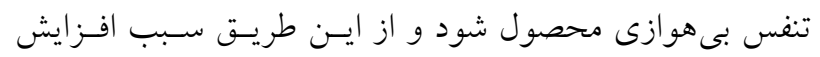
ماند گارى محصول مى شود (Iان).

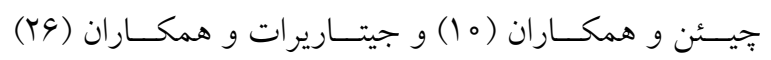

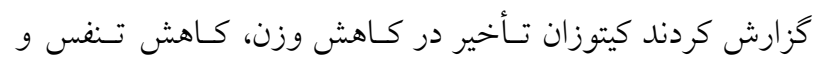

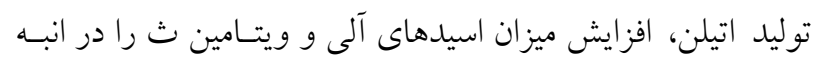

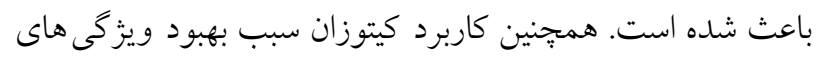

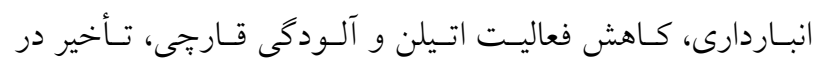

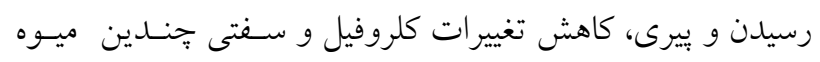

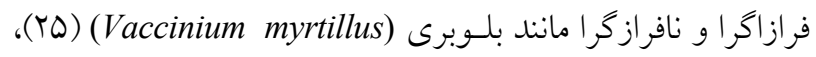

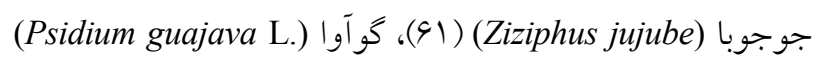

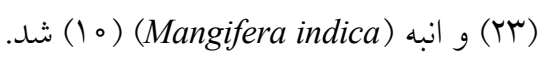

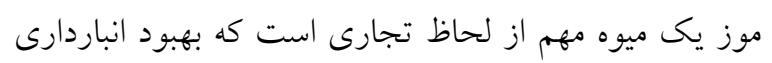

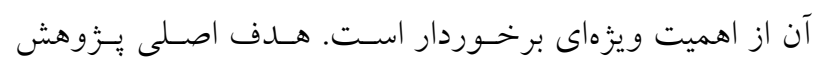

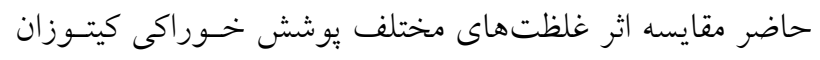

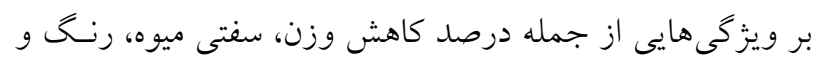

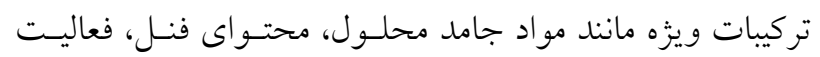

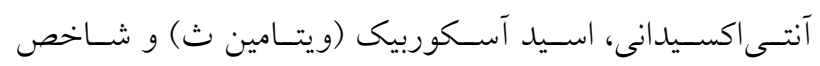

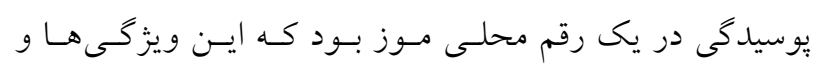
تركيبات كيفيت آن را طلى دوره بيسـت روزه دون انبـاردارى نشـان

\section{مواد و روشها - ماد}

ميوههاى موز رقم كاونديش (Musa acuminata cv. Cavendish)

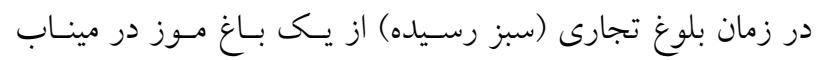

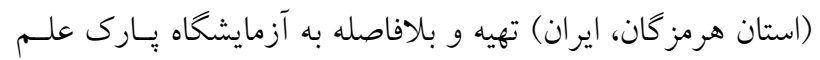

موز يكى از محبوب ترين و مهمترين ميـوهــاى تجـارى در

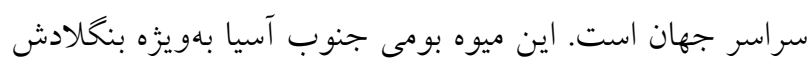

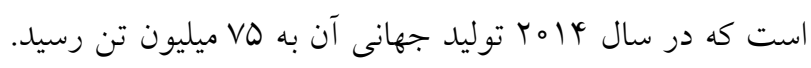

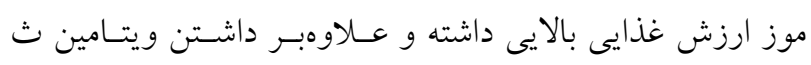

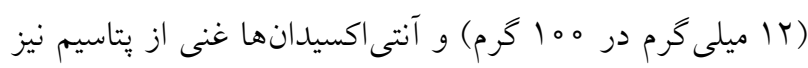

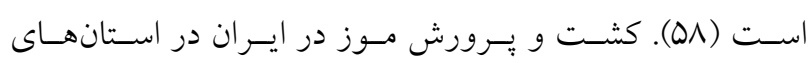

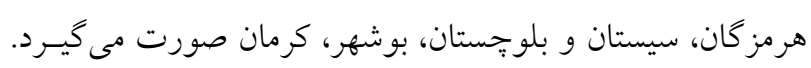

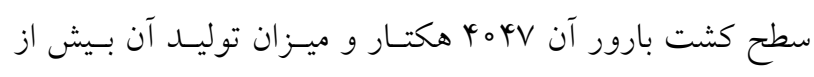

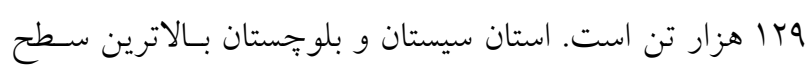
زير كشت را در كل كشور دارا است (1).

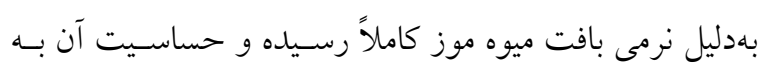

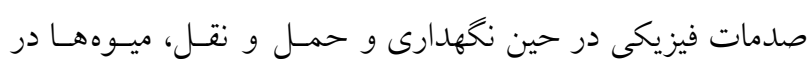

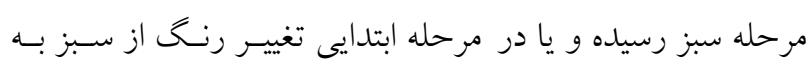

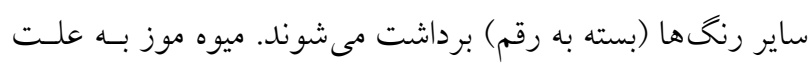

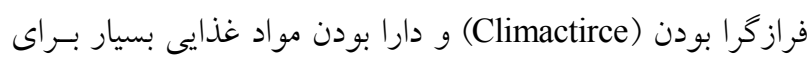

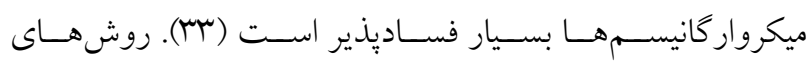

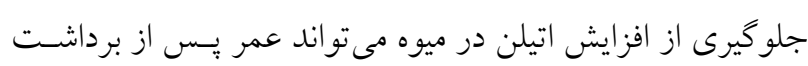

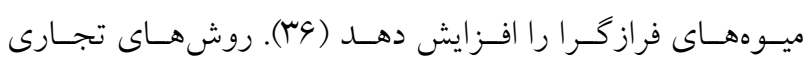

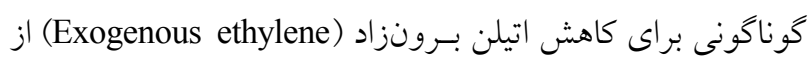

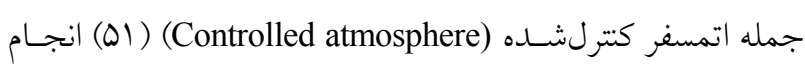

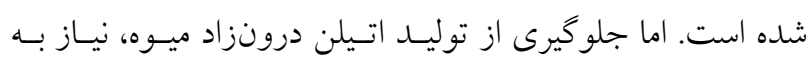

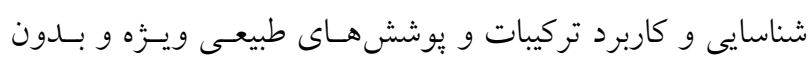
خطر براى سلامتى انسان دارد.

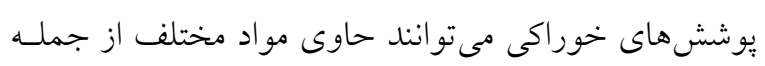

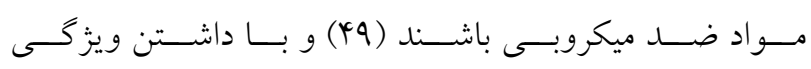

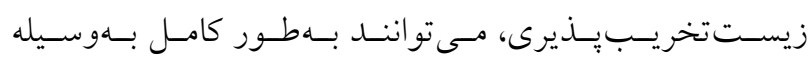

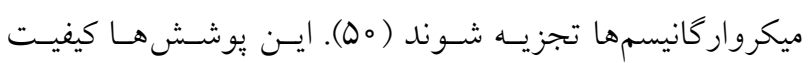

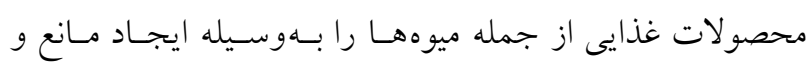

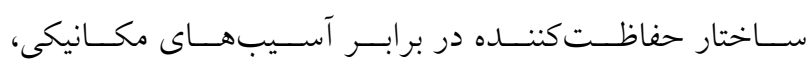
اكسيداسيون، رشد ميكروبى و كازهايى مانند بخار آب، ليبيدهـا،

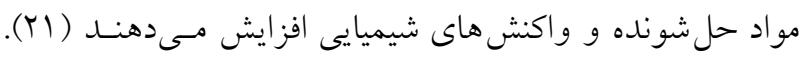




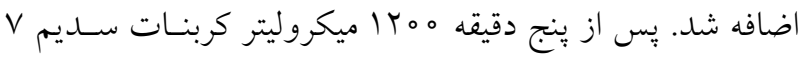

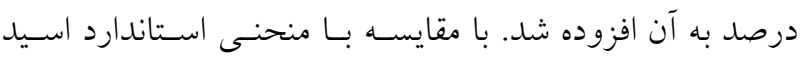

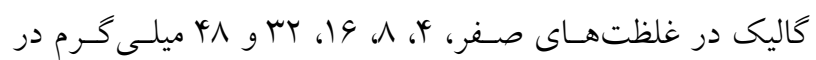

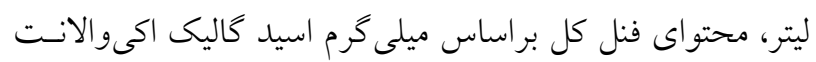

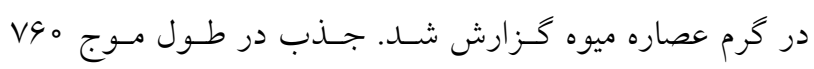

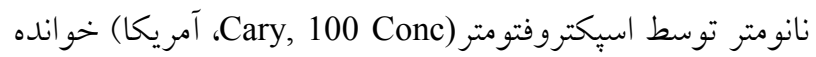

\section{ظر فيت آنتى اكسيدانى}

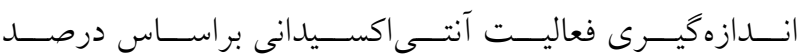
مهار كنــــى (DPH) روش برند و ويليامز و همكاران (9) انجام شد. VQ ميكروليتر از

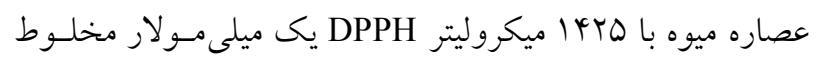

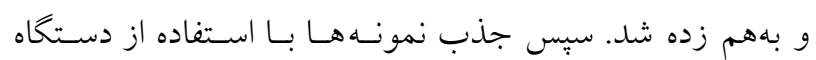

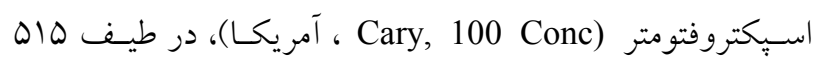

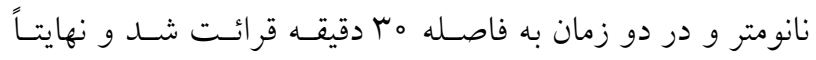
درصد بازدارندگى از طريق فرمول زير بهدست آمد: DPPH درصد بازدارندىى $=\left(A_{r_{0}}-A_{0}\right) / A_{0} \times 100$

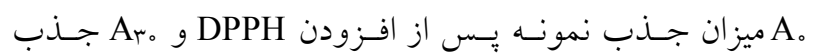

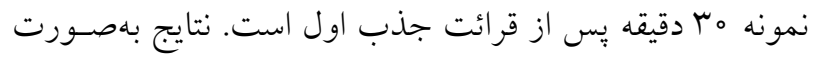
ميلىمولار در هر كرم وزن تر (Fresh weight) بيان شد.

\section{محتواى اسيد آسكوربيك (ويتامين ث)}

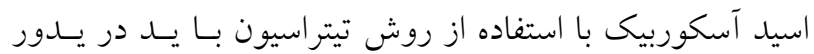

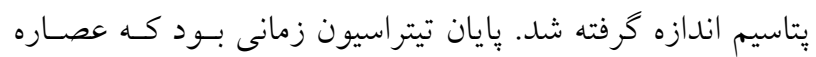

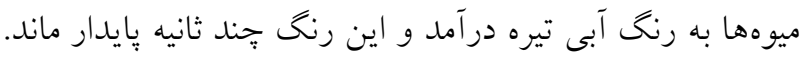

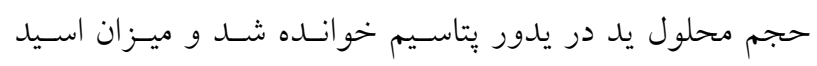

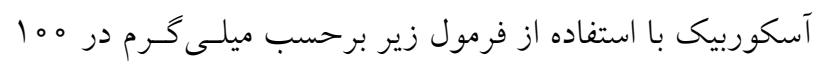

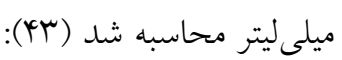
$V_{C}$ مقد $=((Y \times V) /(V c$ Control $)) \times 100$

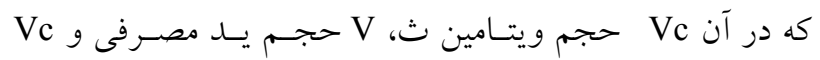
شاهد نيز برابر با اك/ است.
و فناورى همدان متتقل شد. ميوههاى سالم و يكنواخت از لحـاظ

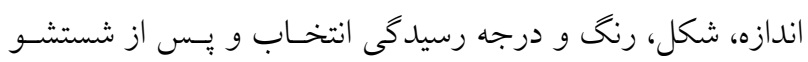

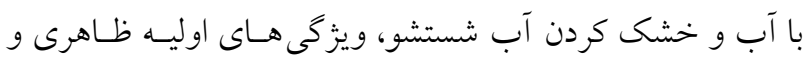

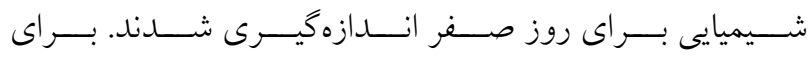

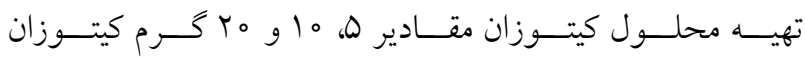

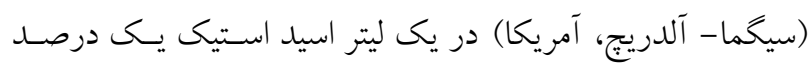

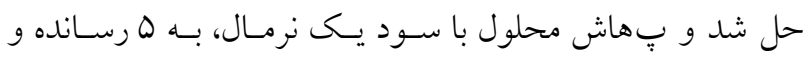

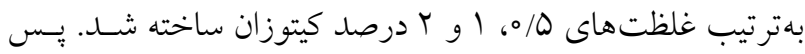
از تهيه محلول كيتوزان نمونه ها بهمدت يكى دقيقه داخـل محلـول

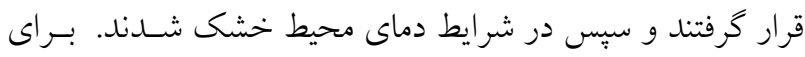

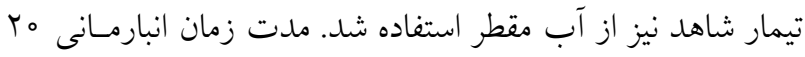

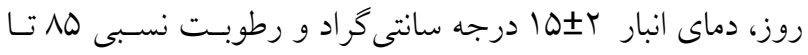

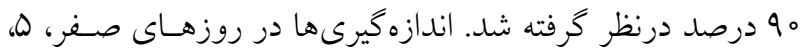

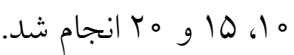

تغييرات وزن و سفتى ميوه

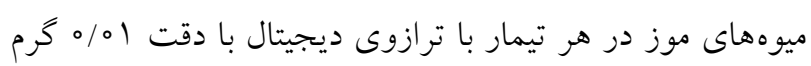

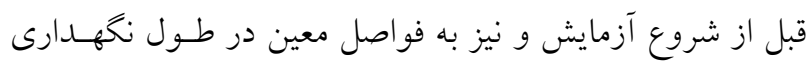

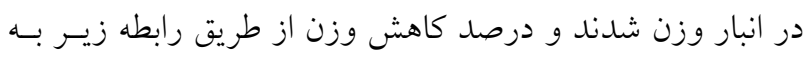

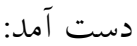

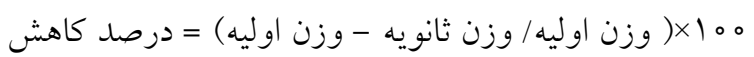
وزن سفتى بافت ميوه (يوست همراه با كُشت) با استفاده از

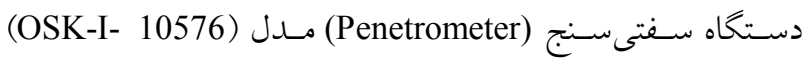
اندازه گيرى و ميزان فشار دستخاه برحسب كيلو گرم بر سانتىمتر مربع محاسبه شد. جهت تعيين محتواى فنل كل بافت ميـوه، از روش سـينخلتون و

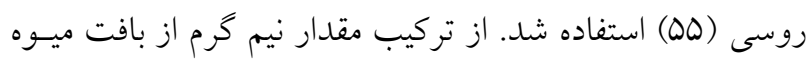

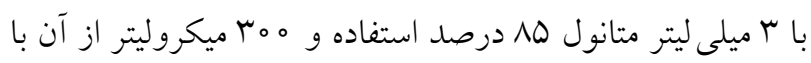

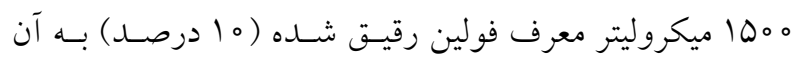


همكاران (4ץ) با اندازه كيرى ناحيه يوسـيده روى يوسـت ميـوه انجام شد و نتايج بهصورت درصد بيان شد.

$$
\text { آناليز آمارى }
$$

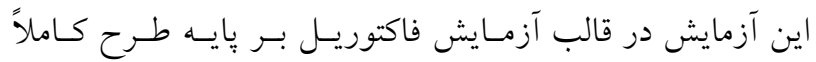
تصادفى با سه تكرار اجرا شد. فاكتور اول شامل سطوح مختلف

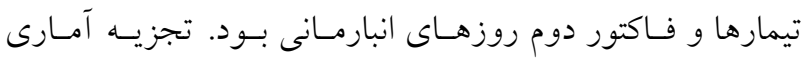
دادهاى تجربى بـه روش مــدل خطـى عمـومى (GLM) و بـــ كمك نرم|فزار SAS (نسخه /9/1) و مقايسه ميانخين ها با استفاده

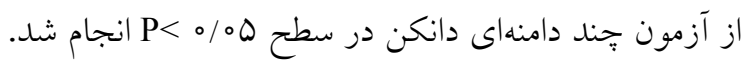

\section{نتايج و بحث

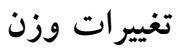

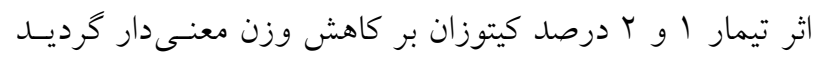
(P< (P/०0) شاهد كاهش وزن بالاترى نسبت به ميوههاى تيمار شده داشـتند

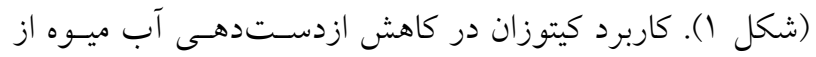
طريق يوست مؤثر بود، بهطورى كه با افـزايش غلظـت كيتـوزان

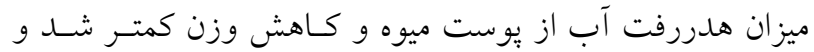
تيمار دو درصد كيتوزان بيشترين اثـر را در كمى كـردن درصـد كاهش وزن داشت. بيشتر ميوههاى فرازگرا، طى دوره رسسيدن و

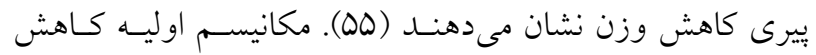

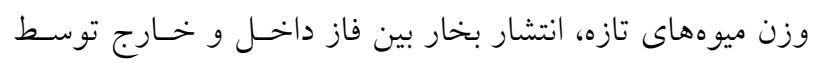
يك شيب فشار بخـار آبميـوه اسـت كـه در نهايـت منجـر بــهـ

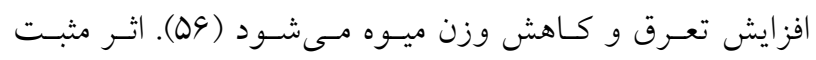

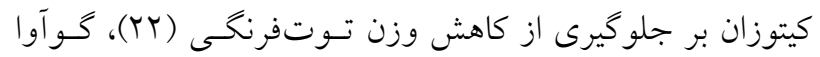
(T) و انبه (Y) گزارش شده است.

سفتى بافت موز به تدريج طى انبارمانى كاهش يافت و در دوره انبارمانى (روز بيستم) بين تيمارهاى مختلف اختلاف معنى دارى در سطح ينج درصد مشاهده شد. در روز بيستم تيمار يـك و دو
آنزيم بلى فنل اكسيداز

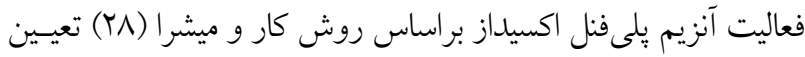

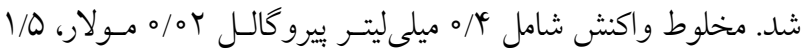
ميلى ليتر بافر تريس r/ه مولار و ه 10 ميكروليتر عصاره آنزيمسى بـود. كاهش در جذب بيرو كالل در مب أنانومتر محاسبه و كزارش شد.

\section{مواد جامد محلول كل (TSS)، بֶهاش (PH)، اسـيديته كـل عصاره ميوه (TA) و شاخص طعم}

براى تعيين مواد جامـــ محلـول بـا استفاده از يـك رفركتـومتر ديجيتالى (ATAGO مدل A.PAL-1 ساخت كشور زاين) ميزان مو اد جامد محلول عصاره ميوه در دماى لم درجه سـانتى گــراد

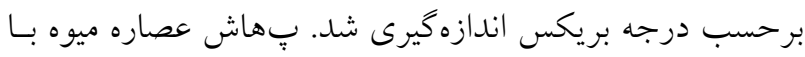

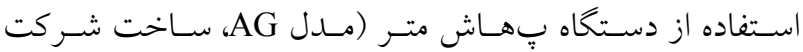

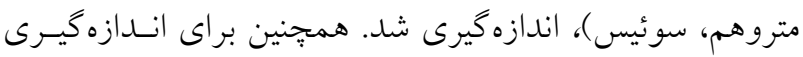

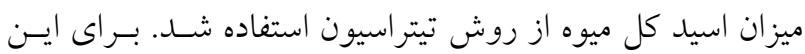

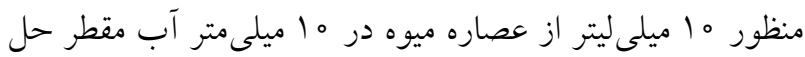

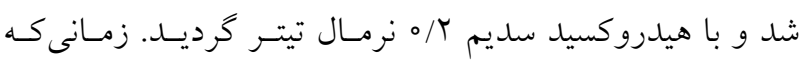

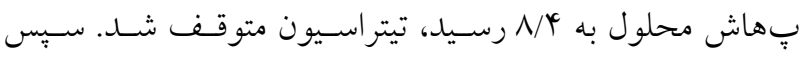

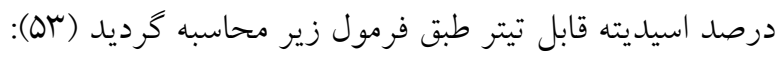

$\mathrm{TA}=\frac{\mathrm{mlNaOH} \times \mathrm{N}(\mathrm{NaOH}) \times \text { acidmeq.factor }}{\mathrm{ml} \text { juice titrated }} \times 100$

شاخص طعم ميوه نيز با استفاده از رابطه TSS/TA محاسبه و كزارش گرديد.

رنگ

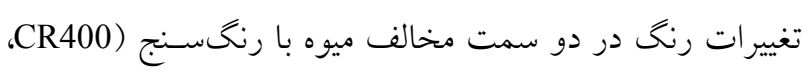

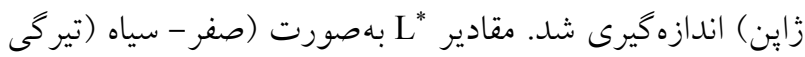

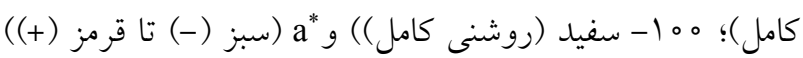

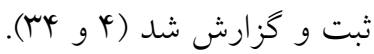

شاخص بوسيدگى (Decay incidence)

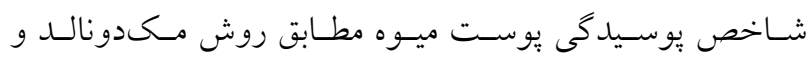




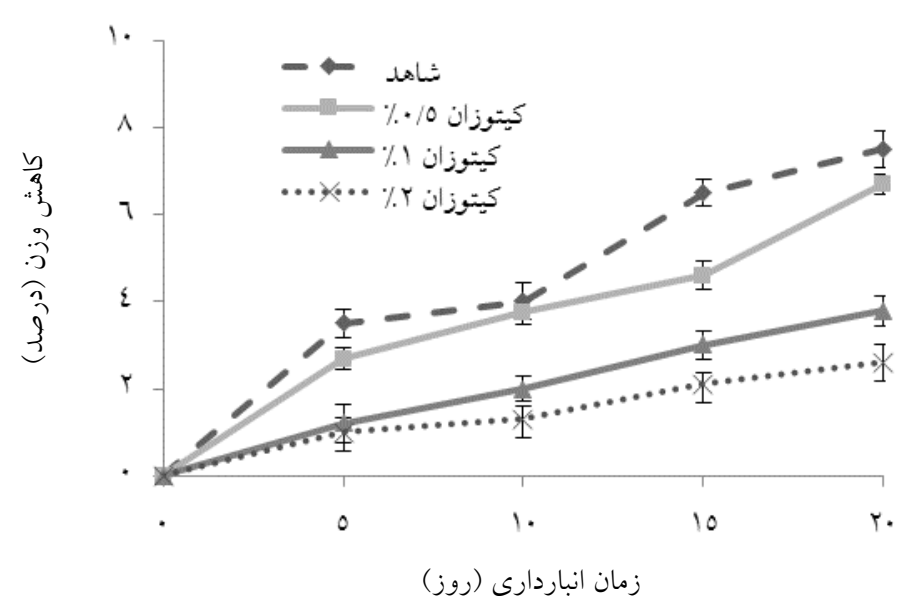

شكل ا. تغييرات درصد كاهش وزن ميوههاى موز تيمار شده با كيتوزان طى مدت نخهدارى در انبار. نوارهاى عمودى روى نمودار در هر دوره نشاندهنده خطاى استاندارد است.

تاننها تشكيل مى دهند كه قبل از دوره رسيدن اين ميزان كاهش

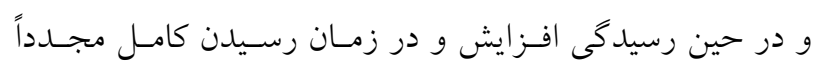

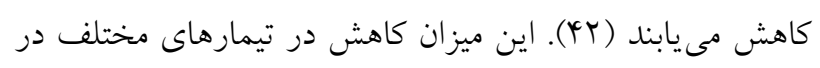

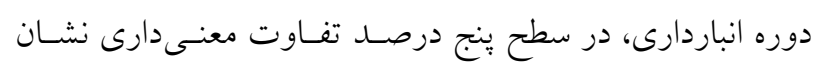

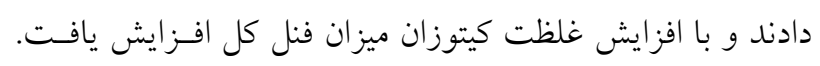

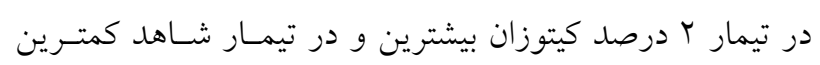

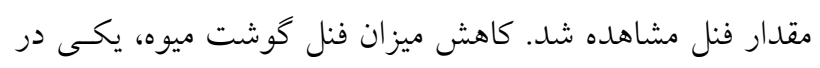

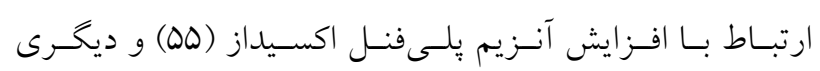
يليمريزهشدن تاننها (ج) طى انبارمانى موز است.

$$
\text { ظرفيت آنتى اكسيدانى }
$$

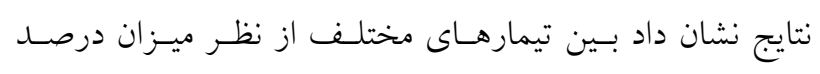

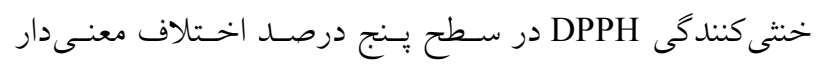

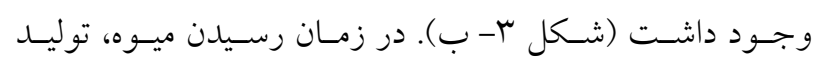

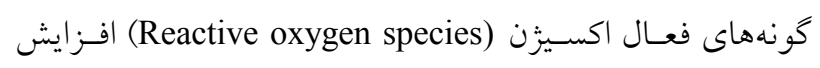

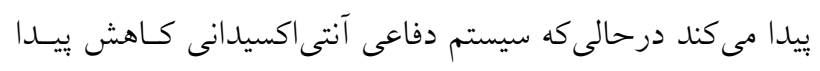

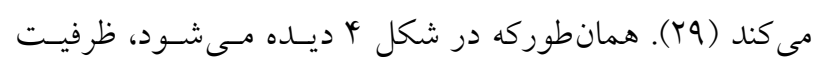

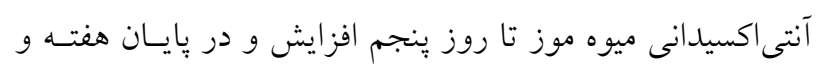

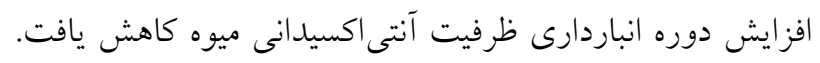

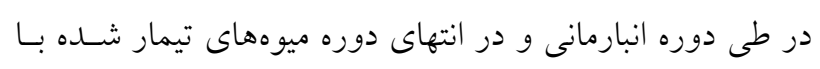

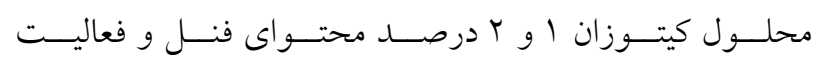

درصد بيشترين سفتى را نشان دادند (شكل r). بهطـورىكـه تـا

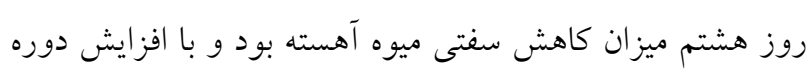

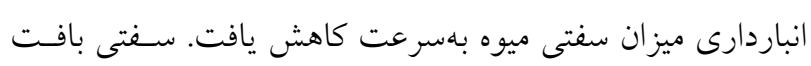

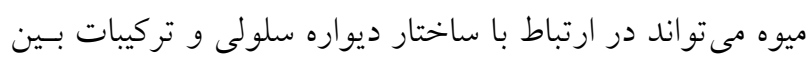

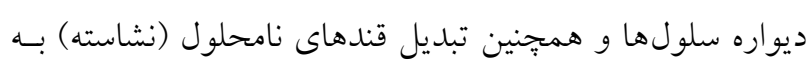
قندهاى محلول (مانند كلوكز و فروكتوز) باشد. تغيير در ساختار

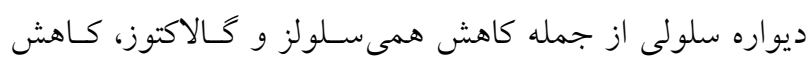

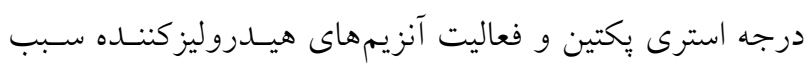

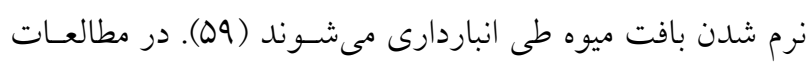

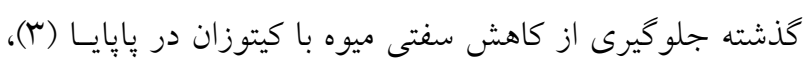

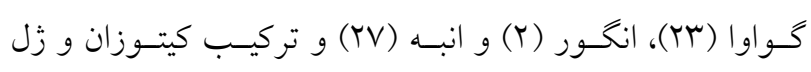

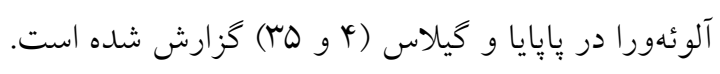
فنل كل شكل r- الف نشاندهنده اثر ميزان غلظت كيتوزان بر ميزان فنل

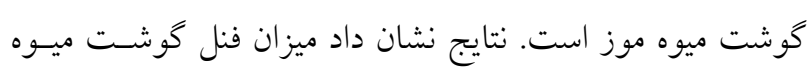

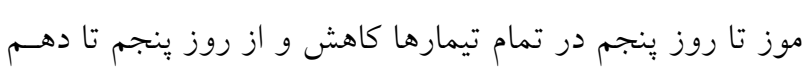

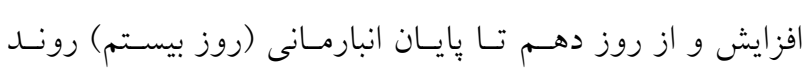

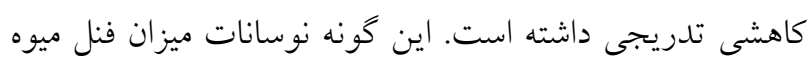

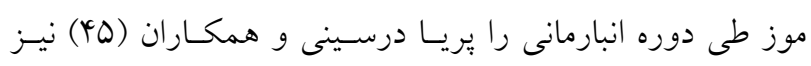

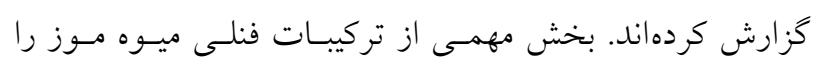




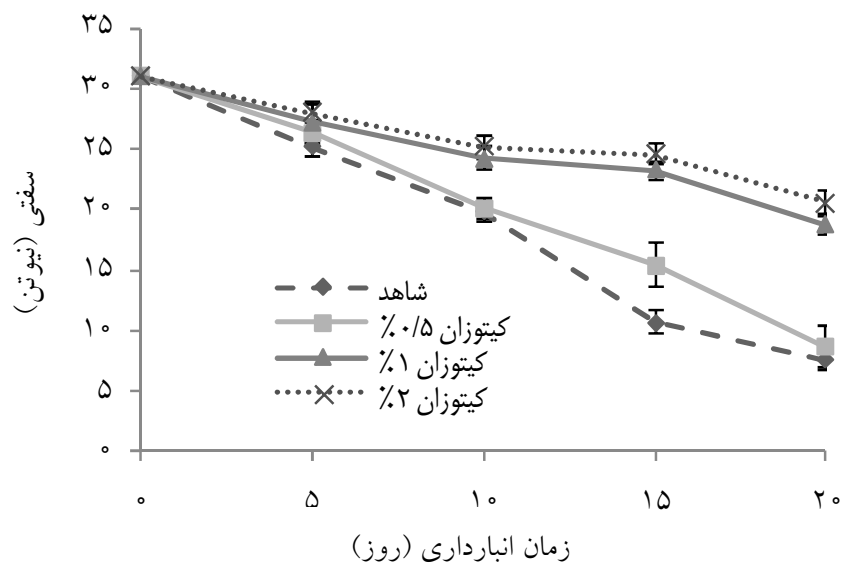

شكل r. تغييرات سفتى ميوهاى موز تيمار شده با كيتوزان طى مدت نخهدارى در انبار.

نوارهاى عمودى روى نمودار در هر دوره نشاندهنده خطاى استاندارد است.

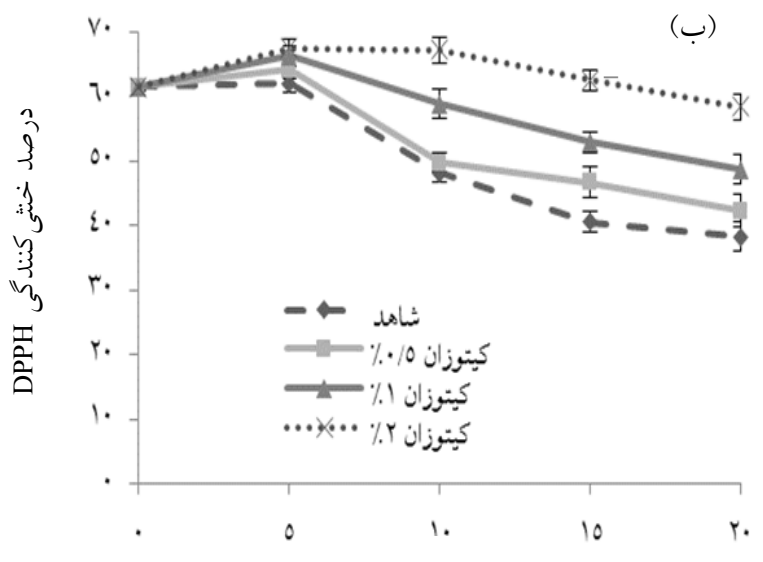

زمان انباردارى (روز)

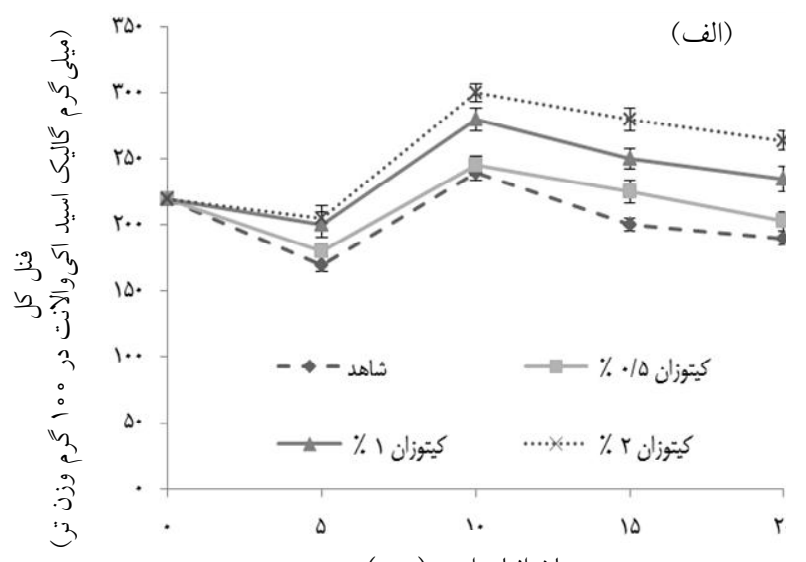

زمان انباردارى (روز)

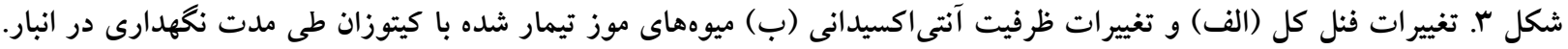

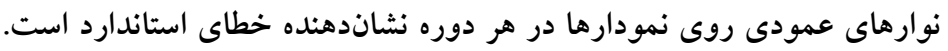

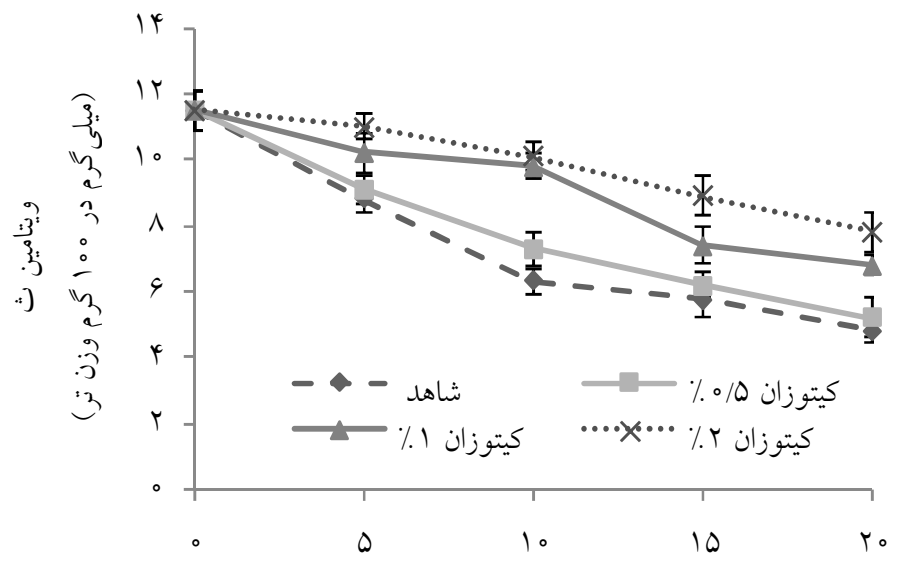

زمان انباردارى (روز)

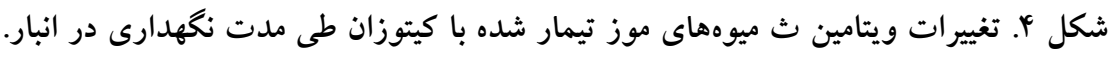

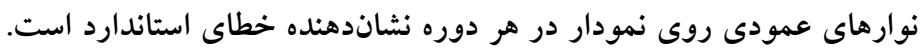


بررسى نتايج نشان داد بين تيمارهاى مختلـف از نظـر ميـزان آنزيم

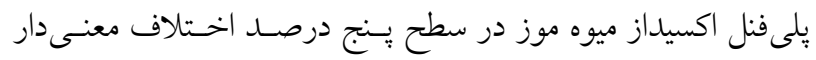

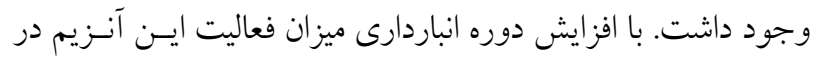

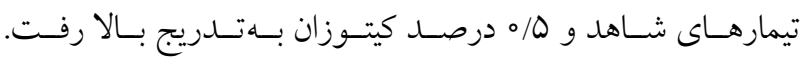

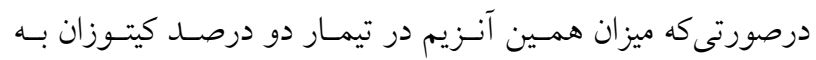

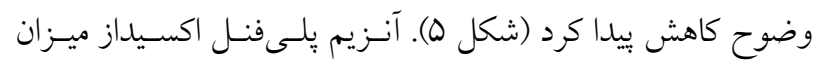

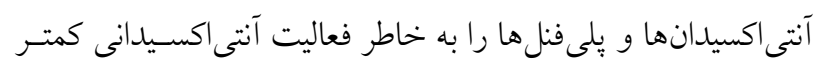

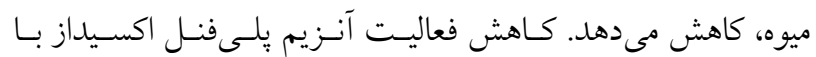

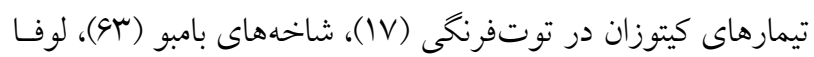
نيز گزارش شده اسـت. مسى (Y) (Luffa cylindrica)

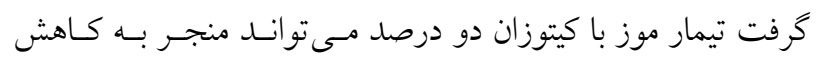

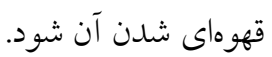

مواد جامد محلول كل (TSS) - (مS) اثر غلظتهاى مختلف محلول كيتوزان بر ميزان مواد جامد محلـول

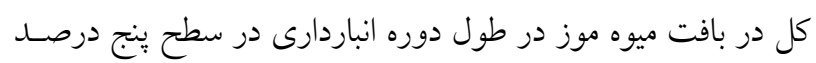

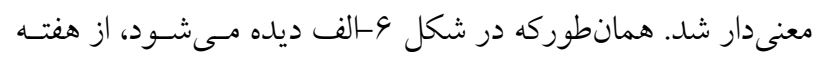

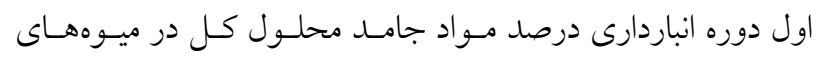

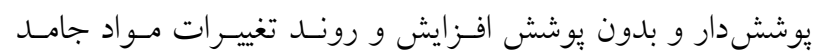

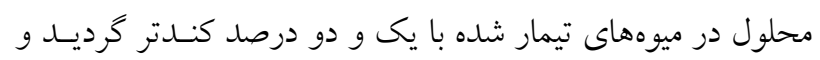

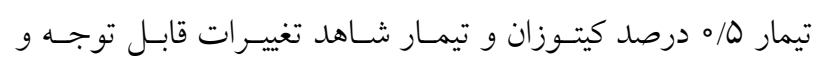
افزايش محسوسى در ميزان مواد جامد محلول كـل در بافـت ميـوه

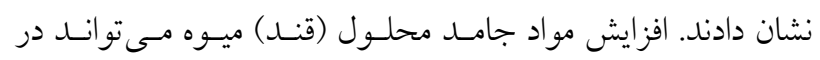

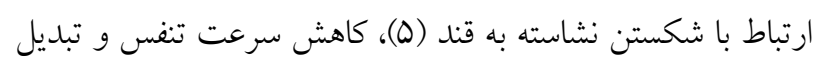

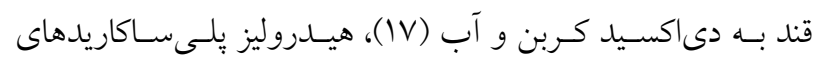

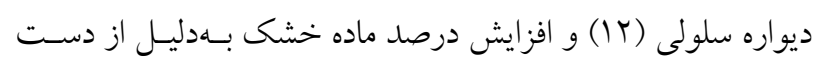
دادن آب (19) باشد. كاهش مواد جامد محلـول كـل در ميـوههـاى

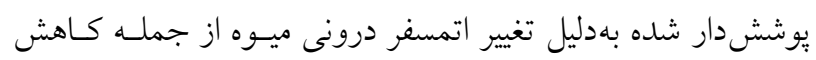

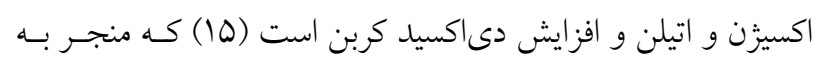

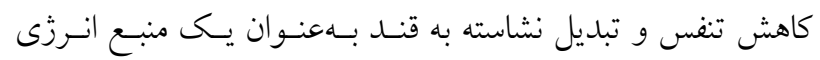

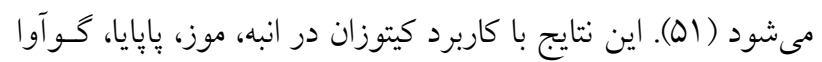

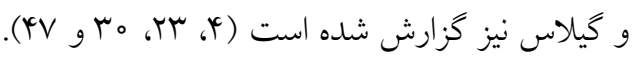

آنتى اكسيدانى بالاترى نسبت به شاهد داشتند. كــزارش شـــه اسـت

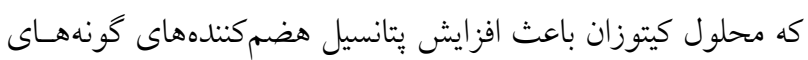

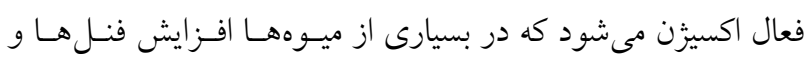

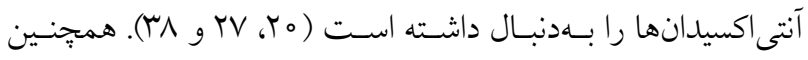

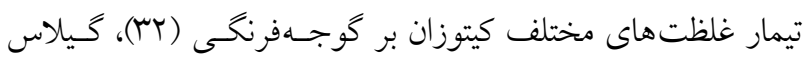

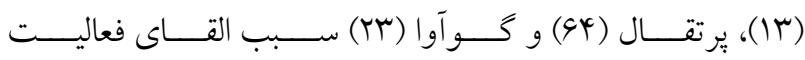
آنزيمهاى آنتسى اكسيدان كاتـالاز (Catalase) سوير اكسيدديسـموتاز و يرو كسيداز (Superoxide dismutase)

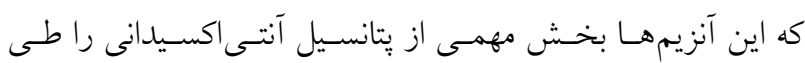

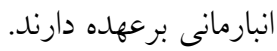

\section{محتواى اسيد آسكوربيك (ويتامين ث)} نتايج نشان داد بين تيمارهاى مختلف در ميزان اسـيد آسـكوربيك السي

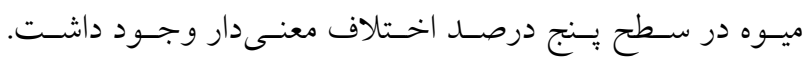

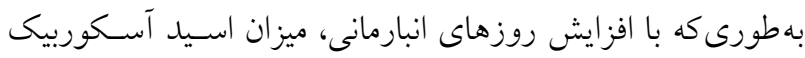

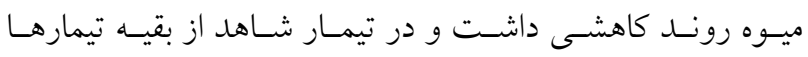

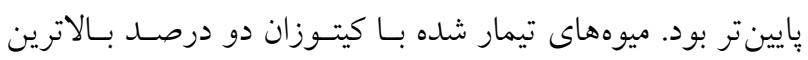

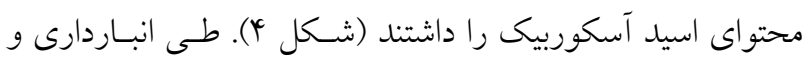
رسيدن ميوه، محتواى ويتامين ث ميوه با فعاليت آنزيم اكسيدكننده

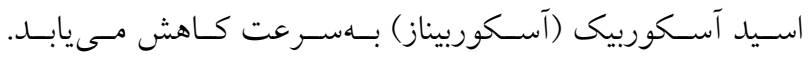

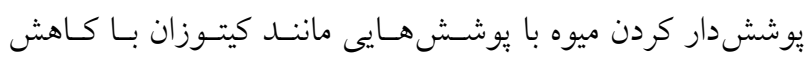
اكسيزن درونى ميوه منجر به افزايش فعاليـت سـيتوكروم اكسـيداز

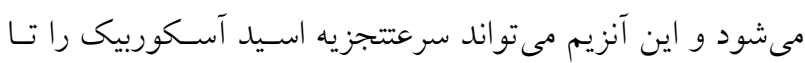

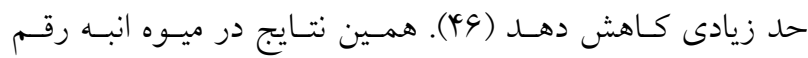

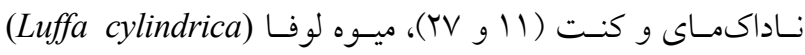

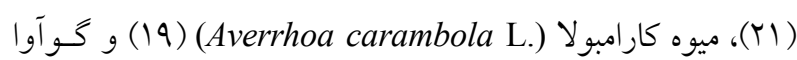
با كاربرد كيتوزان يك يا دو درصـا (Y) (Psidium guajava L.)

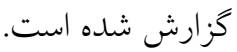

\section{آنزيم بلى فنل اكسيداز}

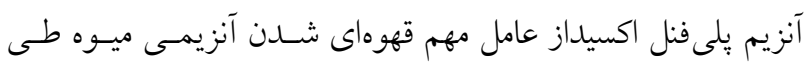
انبارمانى و اكسيد شدن و تبديل فنلها به اورتوكينونها اسـت (QD). 


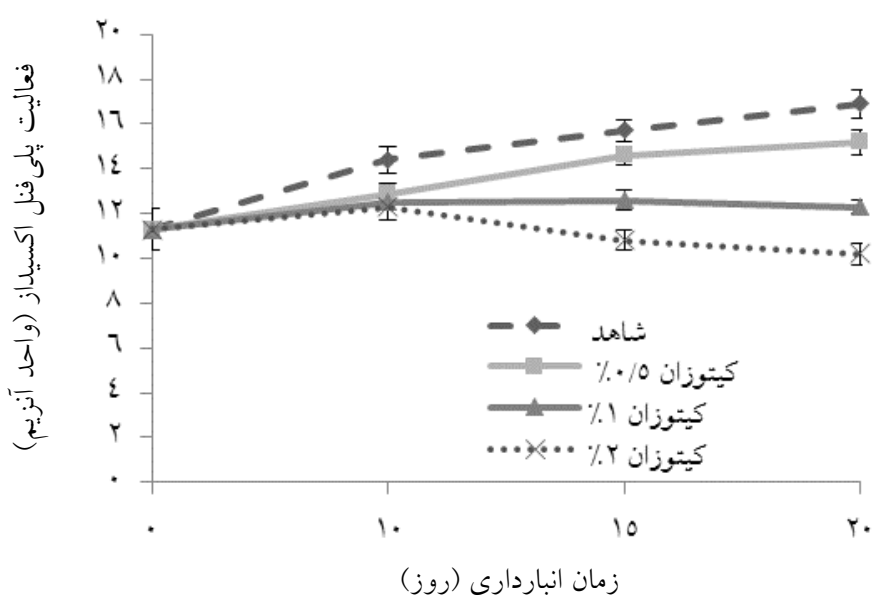

شكل ه. تغييرات يلى فنل اكسيداز ميوههاى موز تيمار شده با كيتوزان طى مدت نخهدارى در انبار.

نوارهاى عمودى روى نمودار در هر دوره نشاندهنده خطاى استاندارد است.
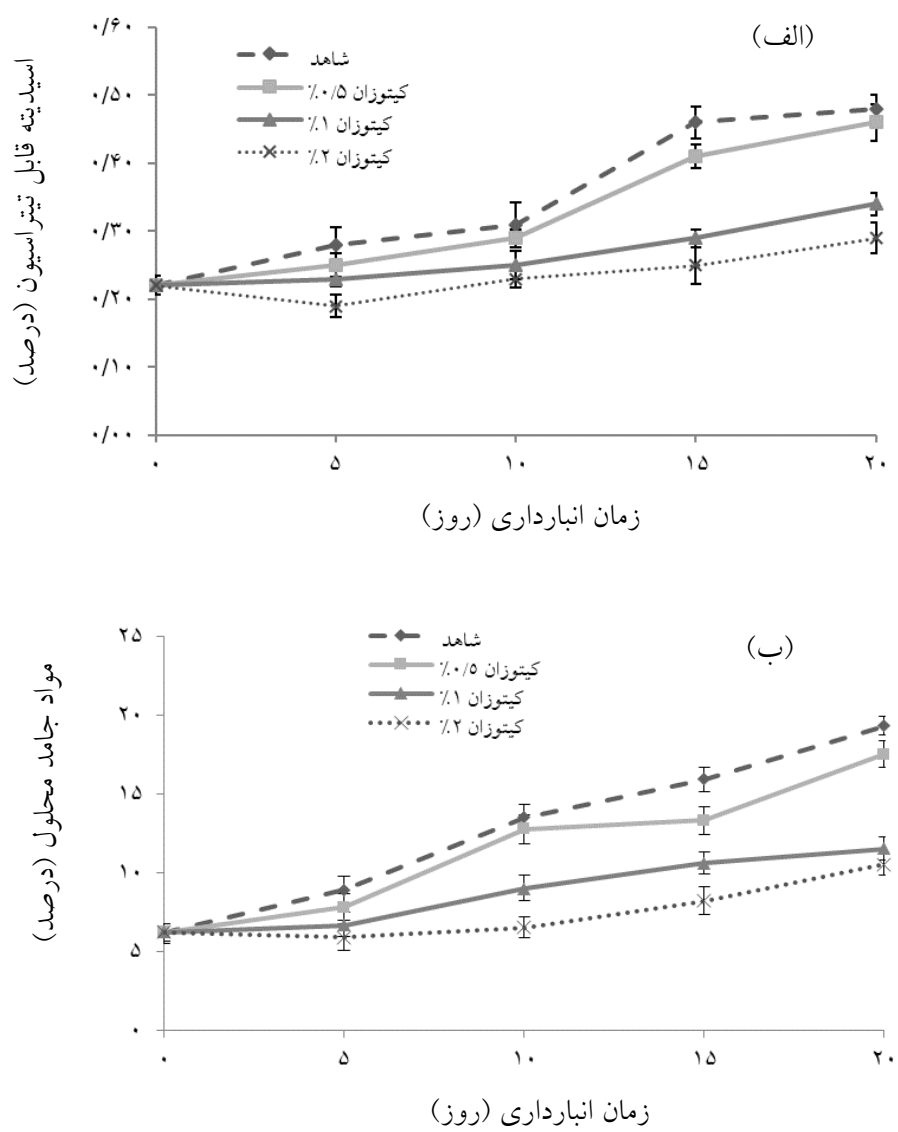

شكل \&. تغييرات اسيديته كل (الف) و تغييرات مواد جامد محلول كل (ب) ميوهاى موز تيمار شده با كيتوزان طى زملى مدت نخهدارى در انبار. نوارهاى عمودى روى نمودارها در هر دوره نشاندهنده خطاى استاندارد است.

بر ميزان اسيد عصاره ميوه در سطح يـنج درصـد معنسى دار شـد.

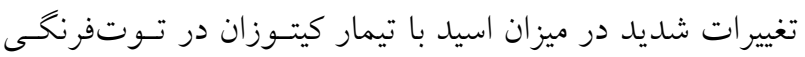

(TA) اسيديته كل ميوه (1) (1) همانطور كه در شكل 9 ب ديده مىشود اثر تيمارهاى كيتـوزان 


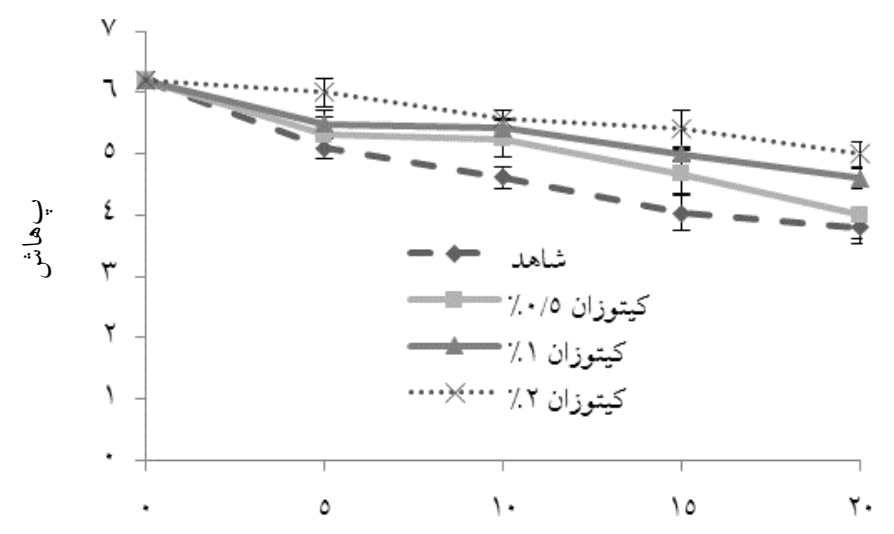

زمان انباردارى (روز)

شكل V. تغييرات بههاش عصاره ميوههاى موز تيمار شده با كيتوزان طى مدت نخهدارى در انبار.

نوارهاى عمودى روى نمودار در هر دوره نشاندهنده خطاى استاندارد است.

(YN)

قهوهاى شدن موز يكى از مهمترين آسيبهـاى انبـاردارى مـوز

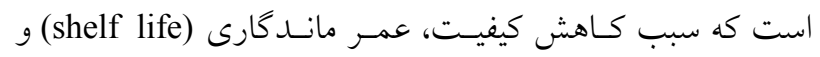

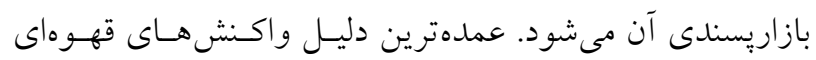

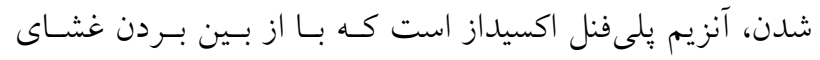

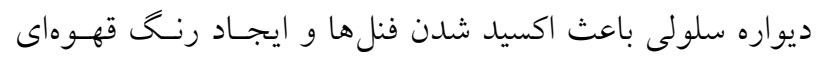

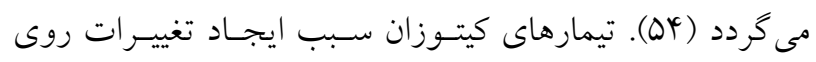

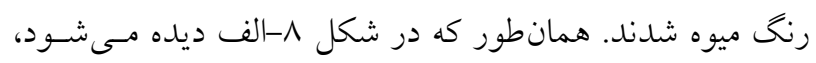

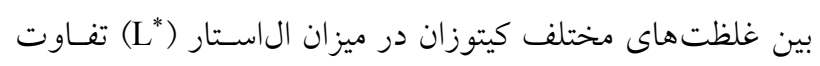

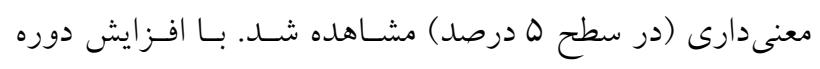

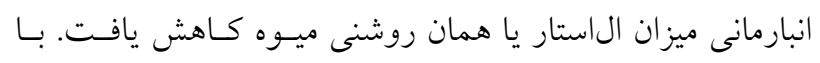

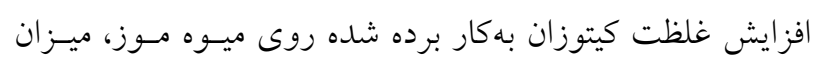

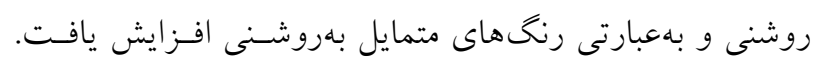

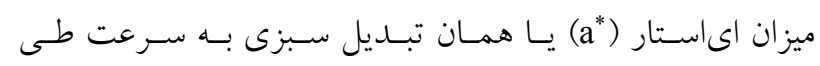

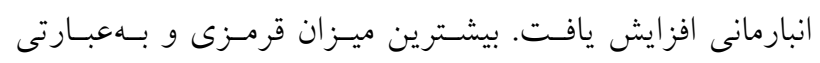

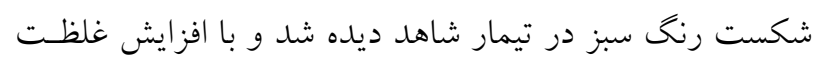

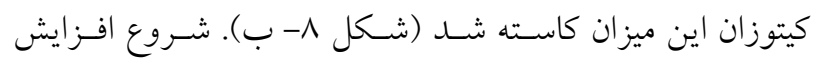

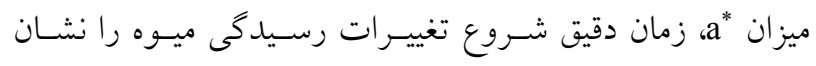

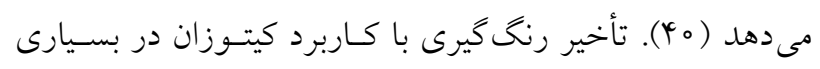

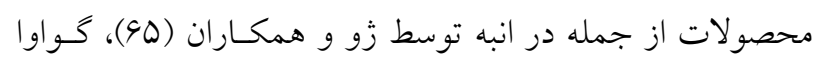

داد اسيديته ميوههاى موز با افزايش دوره انبارمانى افزايش يافتـه

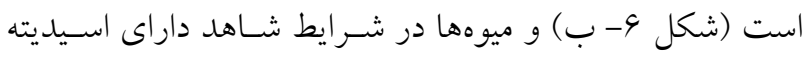

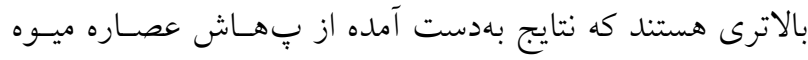

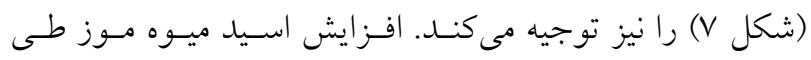

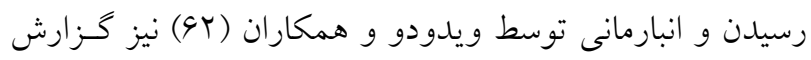

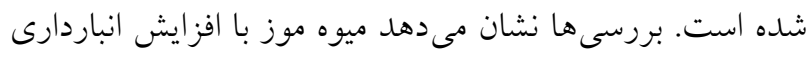

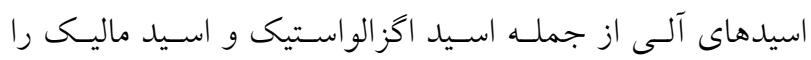

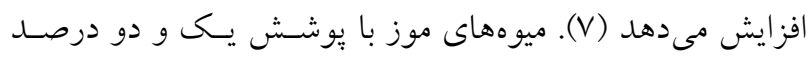

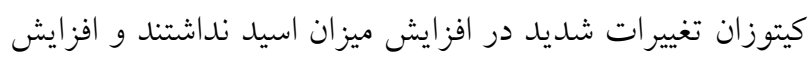

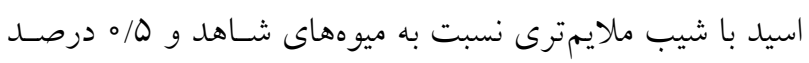

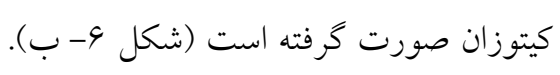
همانطوركه در شكل V ديده مى شود اثر تيمارهاى كيتـوزان بـر

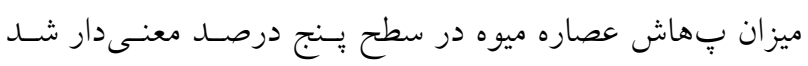

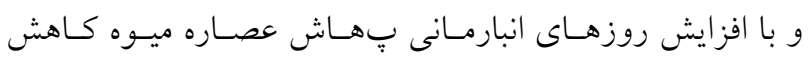
يافت. همجِنين با افز ايش ميزان غلظت كيتوزان بِهاش عصـاره

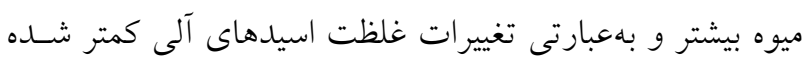

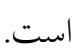




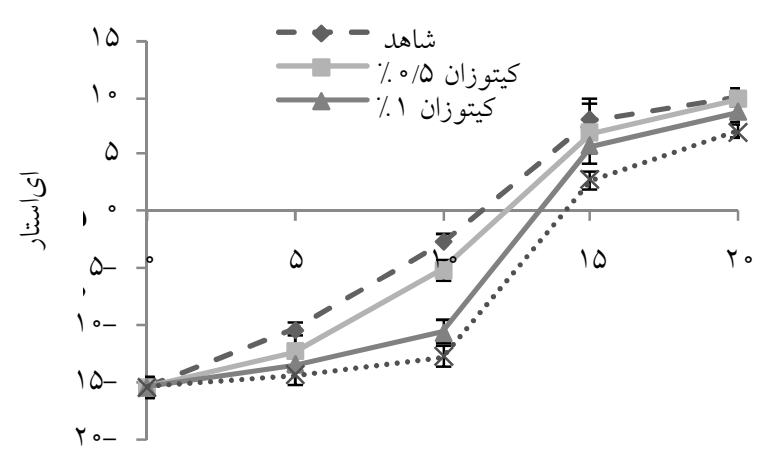

زمان انباردارى (روز)

(ب)

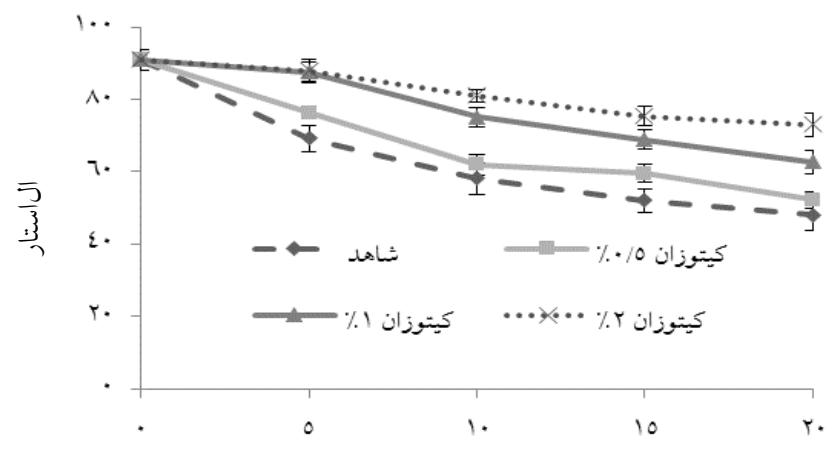

زمان انباردارى (روز)

(الف)

شكل ^ تغييرات الستار (الف) و تغييرات اىاستار (ب) ميوههاى موز تيمار شده با كيتوزان طى مدت نخهدارى در انبار. نوارهاى عمودى روى نمودارها در هر دوره نشاندهنده خطاى استاندارد است.

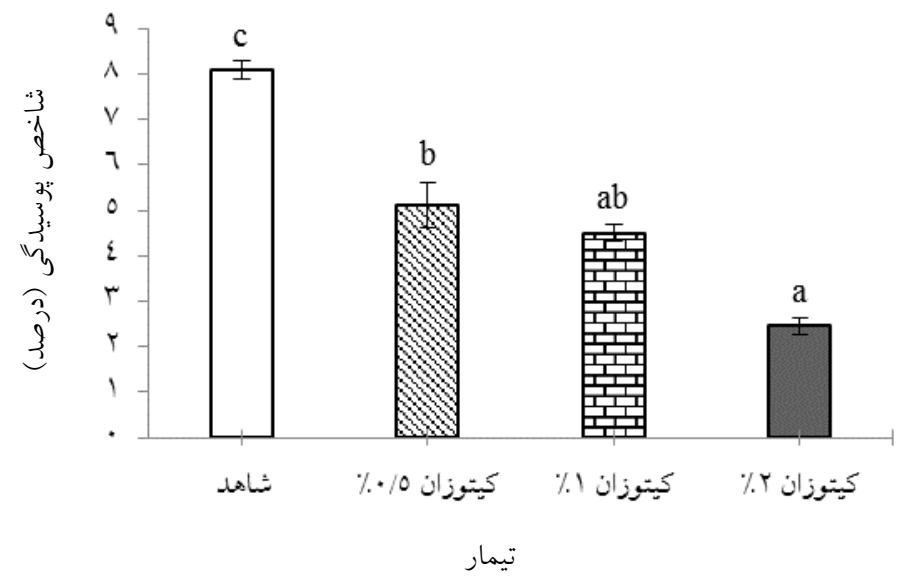

شكل 9. درصد شاخص يوسيدگى ميوههاى موز تيمار شده با كيتوزان طى مدت نخهدارى در انبار. نوارهاى عمودى روى هر ستون

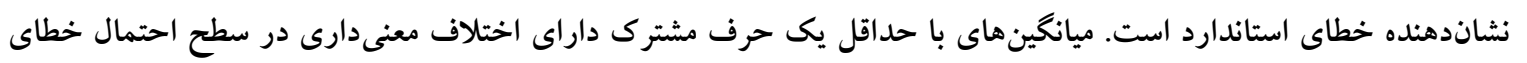
ينج درصد براساس آزمون دانكن نيستند.

نتايج نشان داد بـين تيمارهـاى مختلـف در سـطح بـنج درصــ

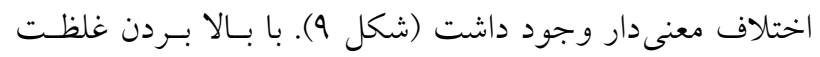

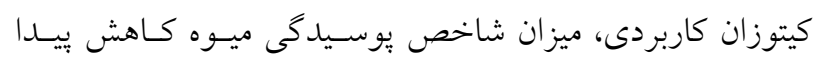

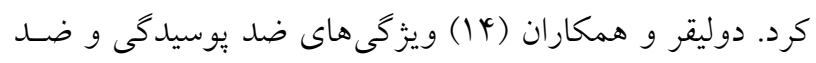

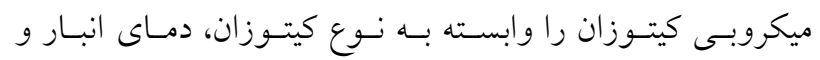

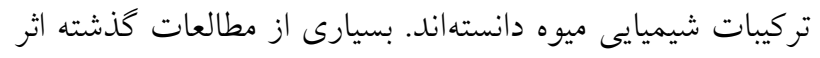

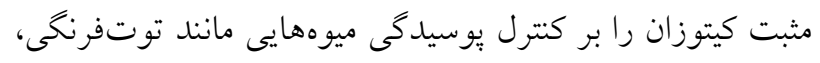

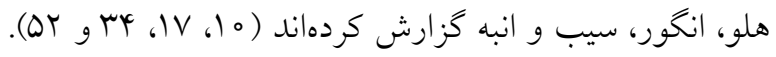

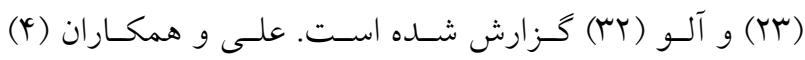

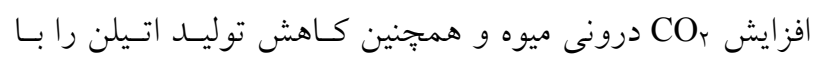

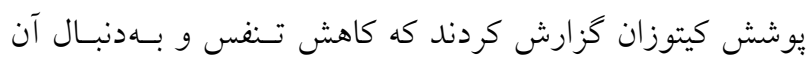

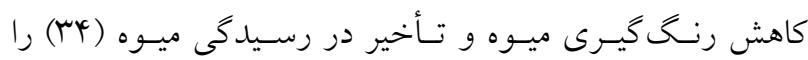
بهنبال دارد.

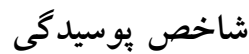

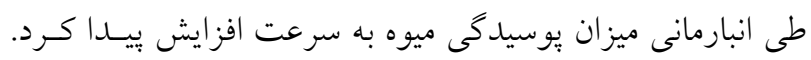




$$
\begin{aligned}
& \text { نتيجه گيرى مرحلهُ اوج تنفسى ميوه موز، ميزان فعاليت آنزيم يلىفنل اكسيداز } \\
& \text { افزايش يافت كه همراه با كسترش قهوهاى شدن بافت ميوه بـود. } \\
& \text { در اين مطالعه استفاده از بوشش خــوراكى كيتـوزان بـهويسزّه در } \\
& \text { بهطوركلى اين بوشش فرآينـد رسـيدگى طبيعى ميـوه، قهـوهاى }
\end{aligned}
$$

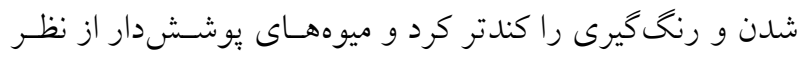

$$
\begin{aligned}
& \text { ظاهرى نيز شرايط بهترى داشتند. } \\
& \text { غلظتهاى يك و دو درصد منجر به افزايش عمـر مانـدگارى و } \\
& \text { افزايش كيفيت ميوه از جمله وزن، سفتى، ظرفيت آنتى اكسيدانى، } \\
& \text { ميزان فنل ها و ويتامين ث شد. در ميوههاى بدون بوشش يس از }
\end{aligned}
$$

1. Agricultural Statistics. 2014. Horticultural products. Ministry of Agriculture, Planning and Economic Department, Office of Statistics and Information Technology 3: 91- 95. (In Farsi).

2. Al-Qurashi, A. D. and M. A. Awad. 2015. Postharvest chitosan treatment affects quality, antioxidant capacity, antioxidant compounds and enzymes activities of 'El-Bayadi' table grapes after storage. Scientia Horticulturae 197: 392- 398.

3. Ali, A., M. T. M. Muhammad, K. Sijam and A. R. Mohamad Zaki. 2005. Effect of chitosan coating on the retention of colour development and firmness of papaya fruit during storage. In: Proceedings of the First International Symposium on Papaya. Genting Highlands, Malaysia. pp. 22-24.

4. Ali, A., T. M. M. Mahmud, S. Kamaruzaman and S. Yasmeen. 2011. Effect of chitosan coatings on the physicochemical characteristics of Eksotika II papaya (Carica papaya L.) fruit during cold storage. Food Chemistry 124: 620-626.

5. Arthey, D. and R. A. Philip. 2005. Fruit processing nutrition, product, and quality management. Brijbasi Art Press Ltd (2nd ed.). Noida. India.

6. Ayala-Zavala, J. F., S. Y. Wang, C. Y. Wang and G. A. Gonzalez-Aguilar. 2007. High oxygen treatment increases antioxidant capacity and postharvest life of strawberry fruit. Food Technology and Biotechnology 45(2) $166-173$.

7. Barker, J. and T. Solomos. 1962. Mechanism of the climacteric rise in respiration in banana fruits. Nature $195: 189$.

8. Bourtoom, T. 2008. Edible films and coatings: characteristics and properties. International Food Research Journal 15(3): 112-120.

9. Brand-Williams, W., M. E. Cuvelier and C. Berset. 1995. Use of a free radical method to evaluate antioxidant activity. Food Science Technology 28: 25-30.

10. Chien, P. J., F. Sheu and F. H. Yang. 2007. Effects of edible chitosan coating on quality and shelf life of sliced mango fruit. Journal of Food Engineering 78: 225-229.

11. Cissé, M., J. Polidori, D. Montet, G. Loiseau and M. N. Ducamp-Collin. 2016. Preservation of mango quality by using functional chitosan- lactoperoxidase systems coatings. Postharvest Biology and Technology 101: 10-14.

12. Comabella, E. and I. Lara. 2013. Cell wall disassembly and post-harvest deterioration of 'Sweetheart' sweet cherry fruit: involvement of enzymic and non-enzymic factors. Pure and Applied Chemical Sciences 1: 1-18.

13. Dang, Q. F., J. Q. Yan, Y. Li, X. J. Cheng, C. S. Liu and X. G. Chen. 2010. Chitosan acetate as an active coating material and its effects on the storing of Prunus avium L. Journal of Food Science 75: 125-131.

14. Devlieghere, F., A. Vermeulen and J. Debevere. 2004. Chitosan: Antimicrobial activity, interactions with Chitosan: antimicrobial activity, interactions with food components and applicability as a coating on fruit and vegetables. Food Microbiology 21(6): 703-714.

15. Dong, H., L. Cheng, J. Tan, K. Zheng and Y. Jiang. 2004. Effects of chitosan coating on quality and shelf life of peeled litchi fruit. Journal of Food Engineering 64: 355-358.

16. Dris, R. and R. Niskanen. 1999. Quality changes of 'Lobo' apples during cold storage. Acta Horticulturae 485 : 125-133.

17. Eshghi, S., M. Hashemi, A. Mohammadi, F. Badii, Z. Mohammad hoseini and K. Ahmadi. 2014. Effect of nanochitosan-based coating with and without copper loaded on physicochemical and bioactive components of fresh strawberry fruit (Fragaria. ananassa Duchesne) during storage. Food and Bioprocess Technology 7(8): $2397-2409$.

18. Ghasemnezhad, M., M. A. Nezhad and S. Gerailoo. 2011. Changes in postharvest quality of loquat (Eriobotrya japonica) fruits influenced by chitosan. Horticultural Environmental Biotechnology 52: 40-45.

19. Gol, N. B., M. L. Chaudhari and T. V. R. Rao. 2015. Effect of edible coatings on quality and shelf life of carambola (Averrhoa carambola L.) fruit during storage. Journal of Food Science and Technology 52: 78-91.

20. Gonzalez-Aguilar, G. A., J. A. Villa-Rodriguez, J. F. Ayala-Zavala and E. M. Yahia. 2010. Improvement of the 
antioxidant status of tropical fruits as a secondary response to some postharvest treatments. Food Science and Technology 21: 475- 482.

21. Han, C., J. Zuo, Q. Wang, L. Xu, B. Zhai and Z. Wang. 2014. Effects of chitosan coating on postharvest quality and shelf life of sponge gourd (Luffa cylindrica) during storage. Scientia Horticulturae 166- 178.

22. Hernandez-Munoz, P., E. Almenar, V. D. Valle, D. Velez and R. Gavara. 2008. Effect of chitosan coating combined with postharvest calcium treatment on strawberry (Fragaria $\times$ ananassa) quality during refrigerated storage. Food Chemistry 110: 428-435.

23. Hong, K., J. Xie, L. Zhang, D. Sun and D. Gong. 2012. Effects of chitosan coating on postharvest life and quality of guava (Psidium guajava L.) fruit during cold storage. Scientia Horticulturae 144: 172-178.

24. Jiang, Y. and D. C. Joyce. 2000. Effects of 1-methylcyclopropene alone and in combination with polyethylene bags on the postharvest life of mango fruit. Annual Application Biology 137: 321-327.

25. Jiang, H., Z. Sun, R. Jia, X. Wang and J. Huang. 2016. Effect of chitosan as an antifungal and preservative agent on postharvest blueberry. Journal of Food Quality 39: 516-52.

26. Jitareerat, P., S. Paumchai, S. Kanlayanarat and S. Sangchote. 2007. Effect of Chitosan on ripening, enzymatic activity, and disease development in mango (Mangifera indica) fruit. New Zealand Journal of Crop and Horticultural Science 35: 211-218.

27. Jongsri, P., T. Wangsomboondee, P. Rojsitthisak and K. Seraypheap. 2016. Effect of molecular weights of chitosan coating on postharvest quality and physicochemical characteristics of mango fruit. Food Science and Technology 73: 28-36.

28. Kar, M. and D. Mishra. 1976 Catalase, peroxidase and polyphenoloxidase activities during rice leaf senescence. Plant Physiology 57: 315-319.

29. Kim, Y., J. K. Brecht and S. T. Talcott. 2007. Antioxidant phytochemical and fruit quality changes in mango (Mangifera indica L.) following hot water immersion and controlled atmosphere storage. Food Chemistry 105: 1327-1334.

30. Kittur, F. S., N. Saroja and H. R. N. Tharanathan. 2001. Poly saccharide based composite coating formulations for shelf-life extension of fresh banana and mango. European Food Research and Technology 213: 306-311.

31. Lin, B., Y. Du, X. Liang, X. Wang and J. Yang. 2011. Effect of chitosan coating on respiratory behavior and quality of stored litchi under ambient temperature. Journal of Food Engineering 102: 94-99.

32. Liu, K., C. Yuan, Y. Chen, H. Li and J. Liu. 2014. Combined effects of ascorbic acid and chitosan on the quality maintenance and shelf life of plums. Scientia Horticulture 176: 45- 53.

33. Malmiri, H. J., A. Osman, C. P. Tan and R. A. Rahman. 2011. Development of an edible coating based on chitosanglycerol to delay 'Berangan' banana (Musa sapientum cv. Berangan) ripening process. International Food Research Journal 18(3): 989-997.

34. Maria, A. R. G., M. S. Tapiab and O. M. Bellosoa. 2008. Using polysaccharide-based edible coatings to maintain quality of fresh-cut Fuji apples. LWT-Food Science and Technology 41(1): 139-147.

35. Martínez-Romero, D., N. Alburquerque, J. M. Valverde, F. Guillén, S. Castillo, D. Valero and M. Serrano. 2006. Postharvest sweet cherry quality and safety maintenance by Aloe vera treatment: a new edible coating. Postharvest Biology and Technology 39(1): 93-100.

36. McDonald, R. E., T. G. McCollum and E. A. Baldwin. 1998. Heat treatment of mature-green tomatoes: Differential effects of ethylene and partial ripening. Journal American Society for Horticultural Science 123(3): 457-462.

37. Mellenthin, W. M. and C. Y. Wang. 1977. The relationship of premature ripening of Bartlett pears to preharvest temperatures. Acta Horticulturae 69: 281-286.

38. Meng, X., B. Li, J. Liu and S. Tian. 2008. Physiological responses and quality attributes of table grape fruit to chitosan pre harvest spray and postharvest coating during storage. Food Chemistry 106: 501-508.

39. Mirdehghan, S. H., M. Rahemi, M. Serrano, F. Guillen, D. Martínez-Romero and D. Valero. 2007. The application of polyamines by pressure or immersion as a tool to maintain functional properties in stored pomegranate arils. Journal of Agriculture Food Chemistry 55: 755-760.

40. Monsalve-González, A., G. V. Barbosa-Cánovas, R. P. Cavalieri, A. J. McEvily and R. Iyengar. 1993. Control of browning during storage of apple slices preserved by combined methods, 4-hexylresorcinol as antibrowning agent. Journal of Food Science 58(4): 797-800.

41. Moore, J. P. 2003. Carotenoid synthesis and retention in mango (Mangifera indica) fruit and puree as influenced by postharvest and processing treatment. PhD. Thesis. University of Florida. U.S.A.

42. Newilah, N. G., P. Brat, K. Tomekpe, P. Alter, E. Fokou and F. X. Etoa. 2010. Effect of ripening on total polyphenol contents of Musa Hybrids and cultivars grown in Cameroon. Acta Horticulturae 879: 45.

43. O’Grady, L., G. Sigge, O. J. Caleb and U. L. Opara. 2014. Effects of storage temperature and duration on chemical properties, proximate composition and selected bioactive components of pomegranate (Punica granatum L.) arils. Food Science Technology 57: 508-515. 
44. Özden, Ç. and L. Bayindirli. 2002. Effects of combinational use of controlled atmosphere: cold storage and edible coating applications on shelf life and quality attributes of green peppers. Europe Food Research Technology 214: 320-326.

45. Priya Darsini, D. T., V. Maheshu, M. Vishnupriya and J. M. Sasikumar. 2012. In vitro antioxidant activity of banana (Musa spp., ABB cv. Pisang Awak). Indian Journal of Biochemistry and Biophysics 49: 124- 129.

46. Pek Z. and L. Helyes. 2010. Color changes and antioxidant content of vine and postharvest ripened tomato fruits. Hortscience 45(3): 466-468.

47. Petriccion, M., F. De Sanctis, M. S. Pasquariello, F. Mastrobuoni, P. Rega, M. Scortichini and F. Mencarelli. 2015. The Effect of Chitosan Coating on the Quality and Nutraceutical Traits of Sweet Cherry During Postharvest Life. Food Bioprocess Technology 8: 394-408.

48. Petriccione, M., F. Mastrobuoni, M. S. Pasquariello, L. Zampella, E. Nobis, G. Capriolo and M. Scortichini. 2015. Effect of chitosan coating on the postharvest quality and antioxidant enzyme system response of strawberry fruit during cold Storage. Foods 4(4): 501-523.

49. Razavi, G., Y. Maghsoudlou. M. Ghorbani and M. Alami. 2015. Anti-fungal effects of hydro-alcoholic extract of thyme (Thymus vulgaris) and methyl carboxy methyl cellulose edible coatings on shelf-life of fresh hazelnut. Journal of Food Technology and Nutrition 3: 39- 48.

50. Reddy, M. M., S. Vivekanandhan, M. Misra, S. K. Bhatia and A. K. Mohanty. 2013. Biobased plastics and bionanocomposites: Current status and future opportunities. Progress in Polymer Science 38:1653-1689.

51. Rohani, M. Y., M. Z. Zaipun and M. Norhayati. 1997. Effect of modified atmosphere on the storage life and quality of Eksotika papaya. Journal of Tropical Agriculture and Food Science 25: 103-113.

52. Romanazzi, G., A. Lichter, F. Mlikota Gablerand, J. L. Smilanick. 2012. Recent advances on the use of natural and safe alternatives to conventional methods to control postharvest gray mold of table grapes. Postharvest Biology and Technology 63: 141-14.

53. Roussos, P. A., V. Sefferou, N. K. Denaxa, E. Tsantili and V. Stathis. 2011. Apricot (Prunus armeniaca L.) fruit quality attributes and phytochemicals under different crop load. Scientia Horticulturae 129: 472-478.

54. Sahraie khosh gardan, A., F. Badiee and S. A. Yassini. 2014. Effect of nano-emulsion coating containing chitosan on Golab apple Golab Kohanz cultivar during storage. Iran Biosystems Engineering 45: 2 113- 120. (In Farsi).

55. Sharma, R. R., C. N. Singh and A. M. Goswami. 2001. Polyphenol oxidase activity in mango (Mangifera indica L.) in relation to flowering behavior and the malformation incidence. Fruits 56: 219-224.

56. Shiekh, R. A., M. A. Malik, S. A. AL-Thabaiti and M. A. Shiekh. 2013. Chitosan as a novel edible coating for fresh fruits. LWT-Food Science and Technology Research 19(2): 139-155.

57. Singleton, V. L. and J. A. Rossi. 1965. Colorimetry of total phenolics with phosphomolybdic-phosphotungstic acid reagents. American Journal of Enology Viticulture 16: 144-158.

58. Suseno, N., E. Savitri, L. Sapei and K. S. Padmawijaya. 2014. Improving shelf-life of cavendish banana using chitosan edible coating. Procedia Chemistry 9: 113 - 120.

59. Valero, D., D. Martinez-Romero, M. Serrano and F. Riquleme. 1998. Influence of postharvest treatment with putrescine and calcium on endogenous polyamines, firmness, and abscisic acid in lemon (Citrus lemon L. Burm cv. 'Verna'). Journal of Agricultural and Food Chemistry 46: 2102-2109.

60. Wang, C. Y. and L. Qi. 1997. Modified atmosphere packaging alleviates chilling injury in cucumbers. Postharvest Biology Technology 10: 195-200.

61. Wang, L. T., H. Wu, G. Z. Qin and X. H. Meng. 2014. Chitosan disrupts penicillium expansum and controls food postharvest blue mold of jujube fruit. Food Control 41: 56-62.

62. Widodo, S. E., Y. C. Zulferiyenni Ginting, F. H. Fazri and D. Saputra. 2015. Effects of 1-methylcyclopropene and chitosan on the fruit shelf-life and qualities of two different ripening stages of 'Cavendish' banana. Journal of Food and Nutrition Sciences 3(12): 54-59.

63. Yang, H., J. Zheng, C. Huang, X. Zhao, H. Chen and Z. Sun. 2015. Effects of combined aqueous chlorine dioxide and chitosan coatings on microbial growth and quality maintenance of fresh-cut bamboo shoots (Phyllostachys praecox, f. prevernalis) during storage. Food and Bioprocess Technology 8:1011-1019.

64. Zeng, K., Y. Deng, J. Ming and L. Deng. 2010. Induction of disease resistance and ROS metabolism in navel oranges by chitosan. Scientia Horticulturae 126: 223-228.

65. Zhu, X., Q. Wang, J. Cao and W. Jiang. 2008. Effects of chitosan coating on postharvest quality of mango (Mangifera indica L. cv. tainong) fruits. Journal of Food Processing and Preservation 32: 770-784. 


\title{
The Effect of Postharvest Chitosan Treatment on the Quality Maintenance of Banana (Musa acuminata cv. Cavendish) during Cold Storage
}

\author{
M. Karimi ${ }^{1}$, M. S. Hosseini ${ }^{2}$ and S. M. Zahedi ${ }^{*}$
}

(Received: March 3-2017; Accepted: June 12-2017)

\begin{abstract}
The aim of this research was to investigate the effect of different concentrations of chitosan coating on the quality and shelf life of a local cultivar of banana. The factorial experiments of this research were conducted based on a complete random design with three replications in a warehouse at $15^{\circ} \mathrm{C}$, with the relative humidity of $85-90 \%$. The treatments consisted of four chitosan concentrations $(0,0.5,1$ and $2 \%)$ and characteristics such as weight, hardness, rottenness, phenol content, antioxidant content, $\mathrm{pH}$, titratable acidity and soluble solid materials, vitamin $\mathrm{C}$, polyphenol oxidase enzyme, level of browning and coloring were measured on the days $0,5,10,15$ and 20 . The results showed that chitosan treatment improved some qualitative characteristics in the banana fruit. Chitosan delayed water loss and weight loss, hardness, ascorbic acid content and coloring. The highest incidence index $(8.09 \%)$ was obtained from the control treatment and its lowest value (2.45\%) was found by applying the $2 \%$ chitosan after 20 days. The contents of the soluble solid materials and organic acids were increased during storage and the banana fruits treated with 1 and $2 \%$ chitosan had the lowest soluble solid materials and acid contents. Also, at the end of the storage period, the fruits treated with 1 and $2 \%$ chitosan had the highest $\mathrm{pH}$, phenol content, and total antioxidant content. Finally, it could be concluded that chitosan treatments with concentrations of 1 and $2 \%$ could significantly increase and maintain the quality of the banana fruit during storage.
\end{abstract}

Keywords: Total antioxidant, Ascorbic acid, Poly phenol oxidase, Incidence index.

1. PhD. Student, Department of Horticultural Sciences, Bu-Ali Sina University, Hamedan, Iran.

2. PhD. Student, Department of Horticultural Science, Hormozgan University, Bandar Abbas, Iran.

3. Assistant Professor, Department of Horticultural Sciences, Faculty of Agriculture, University of Maragheh, Maragheh, Iran

*. Corresponding Author, Email: S.M.Zahedi@maragheh.ac.ir 